\title{
On Teaching Strategies of Junior English Reading from the Perspective of Discourse Function
}

\author{
Ling Wang \\ School of foreign languages, Nanchang Normal University, Nanchang, China
}

\begin{abstract}
Reading is not only one of the difficult problems for students, but also one of the most important teaching parts for teachers. 126 students in Xingfeng Jiudu Middle School were taken as the research objects, and their English reading learning was investigated by means of questionnaire survey, so as to find problems existing in junior English reading teaching. Based on the three characteristics of discourse reading: integrity, comprehensiveness and applicability, the paper analyzes junior English reading teaching strategies from the three aspects of pre-reading, while-reading and post-reading. The research shows that under the guidance of discourse reading theory, using the method of discourse reading teaching is beneficial to stimulate students' interest in reading and improve their reading ability. For English teachers, it is also a good way to improve teaching efficiency and reduce teaching pressure.
\end{abstract}

Index Terms - discourse analysis, junior English reading, teaching strategies

\section{INTRODUCTION}

As we all know, reading plays an extremely important role in English learning. Reading, as a language input activity, is a crucial way for people to obtain information. It can increase the quantity of vocabulary and acquire abundant knowledge. In the National Curriculum of Junior English (2011), it is clearly pointed out that junior middle school students should have accurate translation ability and reading ability, and they can understand and read English books accurately, so as to broaden students' learning way and vision. However, along with the increase of age, many of students do not reach the corresponding level in English reading, even some students gradually lose the interest in learning English. For a long time, due to the restriction of exam-oriented, most teachers in China have been using traditional reading teaching method to guide students, they pay more attention to grammar and the structure of sentences in class. It is no question that they cut the text into pieces and do not take the reading as a whole, many of the English teachers are short of discourse awareness, which leads the inefficiency of English reading teaching. At the same time, because of the age, cognitive level and other limitations, the students lack of logical thinking in the process of English reading, many students still focus on the understanding of the surface meaning and devote themselves to memorizing the words and phrases, more importantly, most of students ignore the understanding and analysis of discourse connotation, cohesion, coherence, etc., so they can not grasp the main idea, context and writer's intention, also, students will lack the ability to understand the inner relationship and appreciate the text (Shi Qinghuan \& Wang Xiaolei, 2019, p.72). As the time goes by, students will lose confidence gradually in reading. Therefore, it is extremely urgent to improve students' awareness of discourse in junior English reading. For the students, it can actively cultivate students' reading literacy by strengthening awareness of the discourse, Due to the lack of discourse awareness, many students can only understand the literal meaning of the passages in English reading and can not accurately understand the specific connotation in different contexts. What is more, it is more difficult to make effective inference by exerting their own imagination. While discourse analysis guides students to skip the word-by-word recognition stage, make them focus on the complete content directly and grasp the reading materials as a whole (Yu Songmei, 2009). Therefore, the improvement of students' discourse awareness can effectively enhance their ability to understand reading materials. Discourse Analysis can help in shaping the teacher's perspective in tackling the task of teaching, reading and composing skills, and also provide a framework by which the teacher can prepare his or her own exercises or revise existing materials to give the students the much needed competence beyond the sentence level (Bertram A. Okolo., 2014,p.62).

\section{THE DEFINITION AND CHARACTERISTICS OF DISCOURSE READING}

\section{A. The Definition of Discourse Reading}

According to the book of Modern Foreign Language Teaching Methodology (Shu Baimei, 2013, p.101), discourse is described as a kind of natural occurring stretch of language occurring in context. In other word, discourse refers to the actual language units and represents a whole, which consists of a series of successive sentences or phrases in the process of communication.

From the perspective of view of functional linguistics, English language is composed of words, sentences, paragraphs and so on, which produce semantic association between these components, and finally form a semantic entirety. Students can understand a passage through the process of analysis and combination. Above all, it is the discourse 
analysis.

To learn a language well, the first step is to pay attention to reading. Reading is the basis and key of language learning. Discourse reading is to start with understanding the whole text, the readers use the language knowledge to scan and skim the important language clues and get a overall impression of reading materials so as to quickly understand the surface meaning of text, and then extract the central idea and important information. Therefore, it is very important to cultivate the awareness of discourse. Discourse awareness can actively improve students' reading level and further make students get the connotation of the article. In the course of time, students can also improve their personal ability of language expression.

\section{B. The Characteristics of Discourse Reading}

Integrity--English reading teaching in junior middle school should focus on the whole teaching. The integrative discourse reading teaching can not only improve students' ability of reading comprehension and accelerate the speed of reading, but also cultivate students' ability to analyze, solve problems and use English (Wang Chunlan, 2012). Even in the initial stage, teachers should also take the cultivation of students' ability to have a overall understanding as the starting point, and strengthen the training of students' ability of predicting the main idea, guessing the meaning of new words, summarizing, reasoning, judging and expressing subjective opinion and so on. The treatment of discourse should follow the idea of overall reading, overall perception, overall grasp, overall understanding, overall output, and should fully reflect this idea in all aspects of class teaching, such as problem setting, activity arrangement, the way of evaluation and so on.

Comprehensiveness--The four skills of listening, speaking, reading and writing in English are all important parts of comprehensive language communication competence and are also the basis of comprehensive ability to use the target language. These four skills are complementary and mutually reinforcing. In discourse teaching, the teachers should try their best to train the training of four skills. In the input stage, the teachers should arrange more exercises about listening and reading. In the output stage, the teacher should arrange some exercises about speaking and writing, at this time, students usually have a general understanding of the article, if it is not consolidated, the content will be forgotten soon. The teachers should give students a chance to express their opinions about this article, which will improve students' ability of writing and expression, at the same time, students will gain great confidence. In every steps of teaching, students' ability of listening, speaking, reading, writing should be reflected and trained. According to discourse analysis theory, reading and reading teaching should be regarded as a comprehensive course of linguistic knowledge, We should use language as a whole to improve students' reading interest and comprehension (Miao Huifeng, 2019).

Applicability--It is required that teacher should not only pay attention to language knowledge, but also focus on the training of language skills. Both of language knowledge and language skills are the components of language ability, which interact and promote each other. English language knowledge is an important foundation for the development of English listening, speaking, reading, writing, but language itself is also one of the goals of language learning. In discourse teaching, the learning of language knowledge should be implemented in listening, speaking, reading, writing. In addition, the teachers should change the tendency of paying too much attention to grammar and vocabulary explanation.

In the traditional English teaching method, students usually are stopped in the input stage, many students can understand the general idea of article and can solve the corresponding exercises, but few of them have the chance to output what they have learned in class, in other word, they do not apply the knowledge to their daily communication, which is often called "dumb English". For second language learners, it is very common and normal, because students and teachers always interpret foreign language from the perspective of native language. However, in the discourse teaching, the teacher often guide students to treat English as their native language, at the same time, students will spend more time learning the background and the related stories about the author. Also, students will guess the author's intention and express their opinion about the text. Students will be more willing and more active to learn English.

\section{RESEARCH METHOD}

Reading is not only the most important and complicated part of English teaching, but also the most valuable part in the examination. It is also a combination of vocabulary, pronunciation, grammar and sentences. In the current exam-oriented education, the reading teaching is often divided into many pieces. Due to the limitation of class time, teachers tend to spend more time analyzing the grammar and structure of sentences, and often ignore that reading needs to start with analyzing the whole passage from the discourse. If students' reading comprehension ability only stays in simple language understanding or mechanical language practice, it is far from reaching the goal of the National Curriculum (Liao Chenyong, 2011). The author made a survey and designed 13 questions. Questions 1 and 2 have a general understanding of students' attitude towards reading learning. Question 3 is about the problems students face when they are reading. Questions 4 and 5 are about the students' preparation before reading class. Questions 6 to 8 are about how students solve problems during reading. Questions 9 and 11 are about how students review and consolidate the content of reading after class. Finally, Questions 12 and 13 are about whether the reading skills taught by teachers are helpful to students in coming reading learning. The author interviewed 126 students who from Xingfeng Jiudu 
Middle School by questionnaire survey. According to this survey, it is not difficult to find some problems in junior English reading teaching.

\section{RESULTS AND DISCUSSION}

\section{A. Research Findings}

As the survey shows, only $37.30 \%$ of the students like English reading, but $81.75 \%$ of the students agree that a lot of reading is useful and helpful for English learning. It also proves that reading plays an important role in English learning and is the key for students to get a better grade in the exams. We should try our best to cultivate their interest in English reading. $72.22 \%$ of the students think the main reason is that their ability of discourse analysis is too weak to understand and master the passage well. Only $10.31 \%$ of the students think that the biggest problem in reading is lack of vocabulary and grammar. $76.98 \%$ of the students can preview the passage before class, they said that if there is no preparation before class, they will feel stressed in class. When the students have new words in the reading, most students choose to guess the meaning by intuition or looking up the word directly, even many students choose to ignore new words while reading. $21.42 \%$ of the students can get the main idea of the passage by fast reading, the others usually get main idea through translating word by word and sentence by sentence. What is more, $90.47 \%$ of the students search for relevant sentences based on keywords or find the topic sentences of the paragraphs to get required information they need. Only $9.53 \%$ of the students can obtain the information they need according to the conclusion of the discourse. After class, $96.03 \%$ of the students review and consolidate the passage through reading more, reciting more, and doing a lot of exercises, $3.97 \%$ of the students choose to organize the framework of the whole passage and build the Mind map at the same time.

The teachers also play an important role in the process of learning English. In this survey, when the teachers finish the content of reading, only $11.11 \%$ of the students can master the main idea and understand the writer's standpoint. Many of students say that the teachers seldom summarize the main idea and standpoint that have been expressed in the passage. Moreover, $84.13 \%$ of the students say the teachers seldom teach the reading skills, but usually these skills are very beneficial to get the accurate information from passage.

According to the data obtained from the above survey, it can be found that there are some problems existing in junior English reading teaching: lack of coherence, lack of expansibility and single teaching mode.

\section{B. Discussion}

According to the data obtained from the above survey, it can be found that there are some problems existing in junior English reading teaching: lack of coherence, lack of expansibility and single teaching mode.

Lack of Coherence--The existing English teaching mode focuses on the lexical and syntactic analysis at the sentence level, ignoring the logical and semantic analysis at the discourse level, which leads to the limited space for students to improve their ability of English reading. Coherence is an important feature of discourse, it is positive to understand text and help students to guess the new words, summarize the main idea, analyze the context and infer the context etc. (Sun Min, 2019: 1). In teaching, many teachers are lack of the awareness of discourse coherence.

For example: Alfred arranged to take golf lessons from the local professions. His dog, a cocker spaniel, was expecting pups again. Andrea had the car washed for the big wedding. She expected Alfred to help her move her new apartment.

In the short passage above, it is meaningful to understand each sentence alone. So, many teachers prefer to translate the short passage sentence by sentence, ignoring the analysis of logical and semantic coherence, that is, the teachers cut this discourse into pieces. However, from the view of the whole passage, it is difficult to understand. At the same time, Due to the shortage of vocabulary, the junior high school students are not good at guessing the new words, so they are accustomed to reading passages by learning and looking up every word. More importantly, they are unable to infer the deep meaning of a passage, resulting in the failure to grasp the author's writing intention. Therefore, in the process of reading teaching, it is very important that guiding students to use appropriate method of coherence, which can build a good foundation for students to comprehend text accurately.

Lack of Expansibility--In current exam-oriented education, most of the teachers do well in catching the testing points, but often neglect that the teaching should start from the perspective of humanism. In the process of reading, it is important to understand the cultural knowledge and the connotation of the article. In addition to, it is also very important how to evaluate this culture correctly. These ideas of reading teaching are often ignored by teachers. First, teachers should pay more attention to the introduction of background knowledge. In order to integrate background knowledge into reading teaching, background knowledge is very important, which can be introduced by the teachers or found from the reading materials. Usually, background knowledge is a complex part, including professional knowledge, social and cultural knowledge. Therefore, besides introducing the relevant professional knowledge, the social and cultural knowledge can not be ignored, because the misunderstandings in reading are often caused by different style of living and different way of thinking. What is more, post reading evaluation is also a significant step in reading teaching. Teachers should encourage students to express their own views about reading materials, and cultivate their independent thinking ability.

Single Teaching Mode--Many English teachers have been adopting the traditional reading teaching mode, it is mainly 
based on the monotonous method from reading, translation to checking. However, as we all know, this teaching method not only neglects students' dominant position, but also leads to students' lack of reading enthusiasm, and it is difficult to achieve the effect of reading. At the same time, many teachers only focus on imparting knowledge and hardly develop the students' motivation and interest in learning English. In teaching, many of teachers spend much time in explaining the rules of grammar and the usages of vocabulary for students, which makes students lose the interest in exploring articles, thus lose the interest in reading. Moreover, Teachers often ignore the cultivation of students' humanistic quality, in the processes of imparting knowledge to students, the teachers usually spend much time as performers instead of designing activities that students participate in. Meantime, students do not have more time for independent learning and the teachers neglect the students' feeling. Due to the single teaching mode and individual differences, the students are more likely to get tired of reading.

\section{TEACHING StRATEgIES OF DisCOURSE ANALYSIS}

\section{A. Teaching Strategies in Pre-reading}

As we all know, the reading is a combination of vocabulary, grammar and sentences. So preview before class is the most important procedure in reading learning, which is essential in building and improving students' cognitive ability. However, in actual teaching, many teachers often ignore this step. In fact, through making preparations before pre-reading, not only can students take the initiative to acquire knowledge efficiently and fully feel the pleasure of success, but also the teacher can greatly reduce the teaching pressure and improve the teaching efficiency. Especially in senior grades, with the length of the passages increasing gradually, the content tends to be more complex, what is more, there will be more vocabulary, sentence patterns, grammar and the cultural knowledge. If students have a sufficient preview, it will greatly reduce the pressure of reading teaching. Firstly, the teachers require students to be familiar with most new words and understand the basic usages. It is very important to remove the obstacles of new words before class. In addition, students are also required to preview the cultural background knowledge in reading, if they can not understand the cultural background, they can not understand the deep meaning of the passage. The application of background knowledge is not only conducive to students' mastery the outline of reading materials, but also conducive to the penetration of ideological education in the teaching process. At the same time, it is beneficial to cultivate students' good moral sentiment and improve their cultural accomplishment.

The lead-in is the prelude and foundation of reading teaching, it is significant to establish the construction of reading discourse. A good lead-in can attract students' attention, controls the class and improves the learning atmosphere, what is more, it can enhance students' positive thinking. There are various ways of lead-in, such as reviewing, asking questions, building scenes, designing games and acting dialogues and so on, which are good choices to start reading teaching. Also, it provides students with the key points of connection of new and old knowledge, which is convenient for students to incorporate new knowledge into the original cognitive structure and greatly reduce the difficulties of learning new knowledge from passages. For example, at the beginning of teaching reading, teachers can create a suitable scene for students to ask questions freely by showing the props in the hands of the teachers. The content of lead-in can involves all kinds of scenes in life, So students can accept the words and sentences of passages naturally in such learning environment, which distracts the difficult points in the discourse reading teaching naturally and ingeniously. It can be seen that the flexible and ingenious methods of lead-in can stimulate students' interest in reading learning and build a pleasant learning atmosphere between teachers and students.

\section{B. Teaching Strategies in While-reading}

Reading teaching is different from vocabulary and grammar teaching, which is an input of comprehensive knowledge. It contains the teaching of vocabulary and grammar, but at the same time, it is also a whole. In the method of discourse reading teaching, teachers should start from the discourse analysis and consider the passage as a whole. It is emphasized that students can form a complete knowledge system, so that students can comprehensively understand and master the structure and main idea of passages. From the macro point of view, students are guided to understand the whole passage and grasp the context, so as to cultivate their discourse awareness. At the same time, in the first reading, the design of tasks and questions is essential in discourse reading teaching, such as judging the truth and falseness of questions, which can increase students' sense of achievement and stimulate their interest in the process of reading.

In the second reading, students are required to have a deeper and more detailed understanding of the text. When encountering complex text structures, English teachers can make use of the intuitiveness of multimedia teaching to promote the quality of discourse teaching, which is conducive to simplify the tedious explanation and abstract description. We all know that while learning a foreign language, due to different culture and lifestyle, it is difficult to explain the complex discourse to students, especially junior middle school students. Multimedia teaching equipment and resources can make the description of discourse more specific and visual. Also, many semantic features and relationships between characters in reading can be expressed by these equipment and resources, so that students can better accept complex knowledge of reading discourse. It can provide a great convenience for English teaching.

\section{Teaching Strategies in Post-reading}

In the process of discourse reading teaching, the final summary is an indispensable part. It is not only a summary of 
language knowledge of the whole reading, but also a summary of ideas and emotional attitudes. In addition, a good summary can make students have a better learning efficiency, at the same time, it is helpful for students to cultivate students' ability of critical thinking. While organizing the structure of the passage, teachers should also give students opportunities to show their views. For example, Mind mapping is often used to construct the level of discourse reading. It can train students' logical thinking and improve the ability to obtain information from the whole passage.

The goal of text discourse teaching is to transform the perceptual input of reading materials into the process of text comprehension. After the completion of reading teaching content, post-reading activities and tasks are the sublimation stage, which is helpful for students to connect their life experiences and interest with new knowledge. Also, it can integrate knowledge and reading skills. Teachers can let the students express the real cases in life after they understand the content they read, and also let the students write their feelings about the content after class. Discourse is the spoken or written language unit in practice, more exercises can enhance students' discourse awareness.

\section{CONCLUSION}

The combination of discourse analysis and junior English reading teaching can provide a lot of development space for Junior English teaching. At the same time, it respects the principal position of students by using the method of discourse reading teaching. Under the guidance of discourse reading theory, Teachers acts as a leader, who guides students to better understand the reading material from the perspective of discourse function. In this paper, first of all, the author analyzes and summarizes the background and significance of this study by combining the research of discourse reading at home and abroad. Next, the definition and the three characteristics (integrity, comprehensiveness and applicability) of the discourse reading are introduced in detail. Then the author takes the 126 students from Jiudu Junior Middle School as the object, and find out problems in current English reading teaching by analyzing the survey data. It is found that many English teachers are lack of coherence and expansibility in teaching reading, in addition, they usually use the single reading teaching mode. In view of these problems, the author finally provides some teaching strategies from the three aspects of pre-reading, while-reading and post-reading, so that these strategies of discourse reading teaching can make up for some shortcomings in traditional teaching. More importantly, the reading teaching mode under the guidance of discourse analysis can increase students' discourse awareness, improve their abilities of grasping reading materials and quickly understand the main idea of text, and finally the students' abilities of reading are improved gradually. Anyway, the author believes that Applying discourse analysis to English reading teaching is a feasible and effective teaching method. With the development of discourse reading teaching, the situation of junior English reading teaching will get better and better.

\section{ACKNOWLEDGMENTS}

This paper is funded by 11531 projects of Nanchang Normal University

\section{REFERENCES}

[1] Bertram A. Okolo. (2014). Discourse Strategies for Improving English Language Reading and Composing Skills. Taylor \& Francis, 22, 62-63.

[2] Liao chengyong. (2011). A preliminary study on the teaching strategy of overall English discourse reading in junior middle school. Foreign language teaching and research, 5, 35.

[3] Miao huifeng. (2019). Application of discourse analysis theory in English teaching in junior middle schools. Bohai university, $3-4$

[4] Shi qing-huan, wang xiao-lei. (2019). Discourse analysis and improvement of foreign language reading ability. Journal of naval university of engineering, 16, 72 .

[5] Shu baimei. (2013). Modern foreign language pedagogy (2nd edition). Shanghai: Shanghai foreign language education press.

[6] Wang chunlan. (2012). Application of discourse holistic teaching method in junior middle school English reading class. Science and education, 3, 29.

[7] Yu songmei. (2009). Discourse analysis teaching method in junior middle school English reading. China rural education, $4,48$.

Ling Wang was born in1967 in Jian, China. She received her bachelor of Art degree in linguistics from Jiangxi Normal University, China in 1995. She is currently an associate professor in the School of Foreign Languages, Nanchang Normal University, Nanchang, China. Her research interests include cross-cultural teaching and teaching methods. Prof. Wang is a member of the Chinese Association of Foreign Language Teacher. 